\title{
ROLE OF 128-SLICE, DUAL-SOURCE CT CORONARY ANGIOGRAPHY AS A NOVEL IMAGING TECHNIQUE IN ASSESSMENT OF IN-STENT RESTENOSIS
}

\author{
Hesham Mahmoud Mansour, Eman Ahmed Shawky Geneidi, Amal Ibrahim Ahmed \\ and Wasila Moustafa Mohammed Eldolify*
}

\begin{abstract}
Department of radiodiagnosis, Faculty of medicine, Ain Shams university, and * Radiodiagnosis Specialist in Manshiet El Bakry General Hospital Cairo, Egypt Corresponding :

Wasila Moustafa Mohammed Mobile01004649651

E mail:

dr.wasila2000@gmail.com

Received: 8/12/2019

Accepted: 5/1/2020
\end{abstract}

Online ISSN: 2735-3540

\begin{abstract}
Background: Over the past 35 years, catheter-based intervention has become the dominant form of coronary revascularization. Percutaneous coronary interventions are increasingly performed. The most important advance in the field of percutaneous coronary interventions was the introduction of coronary stent implantation in the 1990s, which led to reductions in incidence of restenosis. The use of multi-slice CT is gaining increasing acceptance for noninvasive cardiac imaging. Recent years with the new emerging machines have demonstrated successful application of multi-slice CT angiography for the noninvasive assessment of coronary artery disease and the evaluation of coronary artery stents.
\end{abstract}

Aim of the Work: To evaluate the role of 128-slice, dual-source CT coronary angiography as a novel technique in assessment of coronary artery in-stent restenosis.

Patients and Methods: This study included forty patients with prior coronary artery stent implantation. The mean age of the included patients was 58 with an age range between 40 and 73 years. A total of 42 coronary artery stents deployed within 40 patients were included in this study; and assessed by MSCT angiography and they underwent invasive coronary angiography as a gold standard for evaluation of the coronary artery stents.

Results: In an overall view, MSCT angiography compared to the invasive coronary angiography as a gold standard technique gave us a sensitivity of $100 \%$, a specificity of about $83.8 \%$, an accuracy of about $87.1 \%$, positive predective value (PPV) is $61.5 \%$ and negative predective value (NPV) is $100 \%$ in the assessment of the patency of the coronary artery stents, taking into consideration proper standard CT angiography techniques in all cases.

Conclusion: Our study helps to identify factors that influence the assessability of coronary artery stents by 128-slice dual source CT scanner, namely, stent type and diameter. It shows that under certain conditions, the detection of in-stent restenosis might be possible with an accuracy that could permit clinical applications, but the nonassessable stents do not allow the use of MSCT coronary angiography in unselected patients with implanted stents in coronary arteries. So that MSCT angiography as a noninvasive technique can be used for assessment of in-stent restenosis but patients must be carefully selected.

Keywords: Computed tomography, multi slice CT. 


\section{INTRODUCTION:}

Coronary artery stenting has become the most important nonsurgical treatment for coronary artery disease. However, in-stent restenosis occurs at a relatively high rate and this problem has led to the routine use of invasive angiography for assessing stent patency $^{(1)}$.

Although coronary angiography is the clinical gold standard and it is a very effective diagnostic tool for detecting such in-stent restenosis, it's clearly an invasive procedure with its associated morbidity and mortality risks, a noninvasive technique for detecting in-stent restenosis would be of great interest and use for following up patients after coronary angioplasty ${ }^{(2)}$.

Multidetector coronary computed tomography (CT), which is widely performed to assess coronary artery disease noninvasively and accurately, provides excellent image quality. Use of low tube voltage can reduce patient exposure to nephrotoxic contrast media and carcinogenic radiation when using standard coronary $\mathrm{CT}$ with a retrospective ECG-gated helical $\operatorname{scan}^{(3)}$.

Reliable coronary imaging with the use of standard coronary CT is also limited by insufficient spatial resolution, specifically for evaluating small or peripheral vessel disease and the lumen of coronary stents, particularly those with a diameter of less than $3 \mathrm{~mm}$; insufficient temporal resolution, which causes motion and stair-step artifacts; severe coronary calcification; and limited characterization of coronary plaque. Various clinical solutions with current and novel imaging techniques are designed to overcome these issues ${ }^{(4)}$.

Use of a step-and-shoot scan, iterative reconstruction, and a high-pitch dual-source helical scan can further reduce radiation dose. High-definition CT can improve spatial resolution and diagnostic evaluation of small or peripheral coronary vessels and coronary stents. Dual-source CT and a motion correction algorithm can improve temporal resolution and reduce coronary motion $\operatorname{artifacts}^{(4)}$.

A recently introduced state-of-the-art dual-source CT scanner achieves the currently highest temporal resolution. This improved temporal resolution with the use of dual-source CT reduces coronary motion artifacts and makes the image quality of coronary CT not only less dependent on heart rate but also less dependent on the phase of the cardiac cycle during which the image is acquired ${ }^{(5)}$.

\section{AIM OF THE WORK:}

The aim of this work is to evaluate the role of 128-slice, dual-source CT coronary angiography as a novel technique in assessment of coronary artery in-stent restenosis.

\section{PATIENTS AND METHODS:}

Forty patients with past history of fortytwo coronary artery stents implantation were examined between September 2016 and April 2019. All the cases were subjected to both prospective ECG-triggered technique in a 128 -slice dual-source CT angiography (Somatom Definition Flash, Siemens, Germany) and conventional angiography in the Radiology Department of Kobry Al kobba Armed Forcies hospital.

The inclusion criterion for our study was for the patients with past history of coronary artery stent implantation and started complaining of ischemic chest pain.

The exclusion criteria were: Allergy to contrast medium, renal insufficiency (serum creatinine concentration $>1.5 \mathrm{mg} / \mathrm{dL})$, arrhythmias, unstable clinical condition, heart rate above $80 / \mathrm{min}$ not responding to medical preparation and clinically unfit 
patients (inability to perform a breath-hold during the examination).

Patient Characteristics: Baseline information and history were collected including demographic information (age, sex, and weight), all past and current illnesses, allergies, past surgical and medical procedures, and concomitant medications as well as allergies and adverse drug reactions, cardiovascular risk factors and habits, smoking and alcohol use history. All patients had a brief physical examination including vital signs measurement before MDCT.

\section{Methods:}

Patient Preparation: all patients were asked to fast 4-6 hours prior to the examination. Medications are not to be discontinued. Patients were informed about the procedure before the examination. Patient's approval was taken by filling out the consent form. Nursing staff performed a medical assessment including measuring patient heart rate and blood pressure. Right antecubital intravenous line was established. Patients waited and rested for at least 5 minutes after the intravenous line was established to relief anxiety. Before the examination, breath-holding exercises were done until the patients were able to hold their breath properly to be successful of imaging. The heart rate was evaluated before the examination. The examination was done if the heart rate is below 65 beats per minute. Patients with heart rates above 70 beats per minute were given cardio-selective betablocker; $100 \mathrm{mg}$ of Metoprolol orally 1 hour before the study to obtain a stable low heart rate, provided that contra-indications to $\beta$ blockers are excluded (asthma, congestive heart failure, bradycardia or atrioventricular block). Sublingual nitrate $5 \mathrm{mg}$ was administered to the patients with a systolic blood pressure of at least $100 \mathrm{mmHg}, 5$ minutes prior to scanning in order to expand coronary arteries. Once patient heart rate has reached the desired rate, he is transferred to the CT room and made comfortable on the examination table. While he was on the CT table, ECG leads were placed on his chest to monitor the heart. Most patients completed CT angiography with no adverse events.

Contrast Material: A bolus of $70-80$ $\mathrm{ml}$ of water soluble non-ionic contrast (Ultravist $370 \mathrm{mg} / \mathrm{ml}$ Schering, Berlin, Germany) was injected through canula with a flow rate of $5 \mathrm{~mL} / \mathrm{sec}$. This injection was automatically followed by injection of about $40-50 \mathrm{cc}$ of saline at a flow rate of $4 \mathrm{ml} / \mathrm{sec}$ using a programmed dual head power injector pump to maintain good opacification of the coronary vessels with wash out of contrast material from the SVC and right side of the heart that may cause artifacts.

Scan Protocol: All CT examinations were performed on 128-slice Dual source CT scanner (Somatom Definition, Siemens). Patients were positioned supine on the CT table. ECG leads were fixed on the chest wall. A scanogram was taken that presented an AP and lateral views of the examined region. It was used to position the imaging volume of the coronary arteries that extends from the level of carina down to about $1 \mathrm{~cm}$ below diaphragm. The center of the field of view is $2 \mathrm{~cm}$ to the left of the dorsal spine on the AP scout and at the level of the hilum on the lateral scout. No calcium scoring was done for our patients due to the presence of radiopaque coronary stents that would lead to false high scores. Then, automated determination of the starting time using the "Bolus-tracing technique" was done. It means injection of the whole volume of the utilized contrast material as a one bolus at the pre-determined rate. After a delay of about 10 seconds from the start of injection series of axial images at the level of the origin of the left main coronary artery is acquired with an interval of 1 second between subsequent images. The density within the descending aorta is monitored in 
each axial image on a real time base while the region of interest (ROI) carefully avoiding the athermanous calcifications. Time-attenuation curves were generated. When the density within the descending aorta exceeds $120 \mathrm{HU}$ (i.e. the contrast started to arrive), the scanning is triggered with a delay of further 3 seconds (time needed for the table movement to the cranial start position while the patient is instructed to hold breathing). This time delay also allows for increase in the contrast concentration at the ascending aorta and coronary arteries. It is to be noted that the axial images taken at the "Bolus-tracing technique" are of low radiation dose with a $120 \mathrm{KV}$ and $40 \mathrm{mAs}$ (not of diagnostic value). This is to reduce the radiation exposure. Prospective ECG tube-current modulation (ECG pulsing) for radiation dose reduction was used for all patients and then the volume data set was taken. Patients were automatically instructed to maintain an inspiratory breath hold while the $\mathrm{CT}$ data and the ECG trace were acquired. No adverse reactions were noted due to contrast material. Despite that the CT scan is completed within minutes; the total examination time was around 10-15 minutes.

MDCTA Data Analysis: Analysis of scans was performed at a workstation equipped with dedicated cardiac postprocessing software. Data sets were evaluated on original axial, multiplanar, and curved multiplanar reformations. Visibility of the stent was considered: Good when the stent lumen was visible and contrast attenuation of the lumen could be evaluated qualitatively without the influence of partial volume effects, metal artifacts of stents, or cardiac motion artifacts. Adequate in presence of image-degrading artifact that didn't interfere with evaluation with moderate confidence. Poor in the presence of image-degrading artifacts when the evaluation is possible yet only with low confidence. Nonassessable when the imagedegrading artifacts were severe enough to prevent differentiation between the significant stenosis and occlusion. These stents were usually of narrow caliber (2.5 $\mathrm{mm}$ or less) with thick struts and marked blooming artifacts which indicates further confirmation by invasive diagnostic angiography. In assessable stents, To assess for significant rest enosis ( $\geq 50 \%$ narrowing of the luminal diameter), we evaluated the stent and the artery segments within $5 \mathrm{~mm}$ of the stent distally and proximally. Stents were visually evaluated and defined as: Patent with no visible neointimal hyperplasia (absence of low-attenuation areas related to neointimal tissue). Patent with non occlusive neointimal hyperplasia (longitudinal lowattenuation areas along the stent wall observed as a rim of hypo-attenuation between the stent and the contrast enhanced vessel lumen with residual patent lumen $>50 \%$ ). Patent with in-stent rest-enosis (longitudinal and transverse low-attenuation areas along the stent wall with residual patent lumen $\leq 50 \%$ ). In-stent occlusion (complete loss of contrast enhancement inside the stent lumen).

\section{RESULTS:}

This study included forty patients with past history of coronary stent implantation, they underwent invasive coronary angiography as a gold standard for evaluation of the patency of the coronary stent.

The mean age of the included patients was 58 with an age range between 40 and 73 years. Male patients were $36(90 \%)$ while females were $4(10 \%) .20 \quad(50 \%)$ had positive family history for premature coronary artery disease, $35(87.5 \%)$ had diabetes mellitus. 37 (92.5\%) had hypertension, $27(67.5 \%)$ were smokers, 33 $(82.5 \%)$ had dyslipidemia.

A total of forty-two coronary artery stents implanted within 40 patients were included in this study; and assessed by 128 slice dual-source CT underwent invasive 
coronary angiography and after correlation of the MSCT data with the invasive coronary angiography data, they were classified as follows: 3 stents were nonassessable by MSCT due to heavy stent struts and narrow caliber (all of them are 2.5 $\mathrm{mm}$ in caliber) and proved to be patent stents by invasive coronary angiography. Within the 39 assessable stents the following results were found:

1) Twenty-six stents: were reported to be patent by MSCT and proved their patency by invasive coronary angiography (their calibers are : 10 of $3 \mathrm{~mm}, 7$ of $3.5 \mathrm{~mm}, 7$ of $2.75 \mathrm{~mm}$ and 2 of $2.5 \mathrm{~mm}$ ).
2) Nine stents: were reported to have suspected in-stent restenosis by MSCT and the invasive coronary angiography revealed that 4 of them have in-stent restenosis (their calibers are: 2 stents of $2.5 \mathrm{~mm}$ and 2 of 2.75 $\mathrm{mm}$ ) while 5 stents proved to be patent by invasive coronary angiography ( 2 of $3 \mathrm{~mm}$, 2 of $2.5 \mathrm{~mm}$ and one of $2.75 \mathrm{~mm}$ in caliber).

3) Four stents: were reported to be totally occluded by MSCT and proved their occlusion by invasive coronary angiography (their calibers are: one stent of $3.5 \mathrm{~mm}, 2$ of $3 \mathrm{~mm}$ and one of $2.5 \mathrm{~mm}$ ).

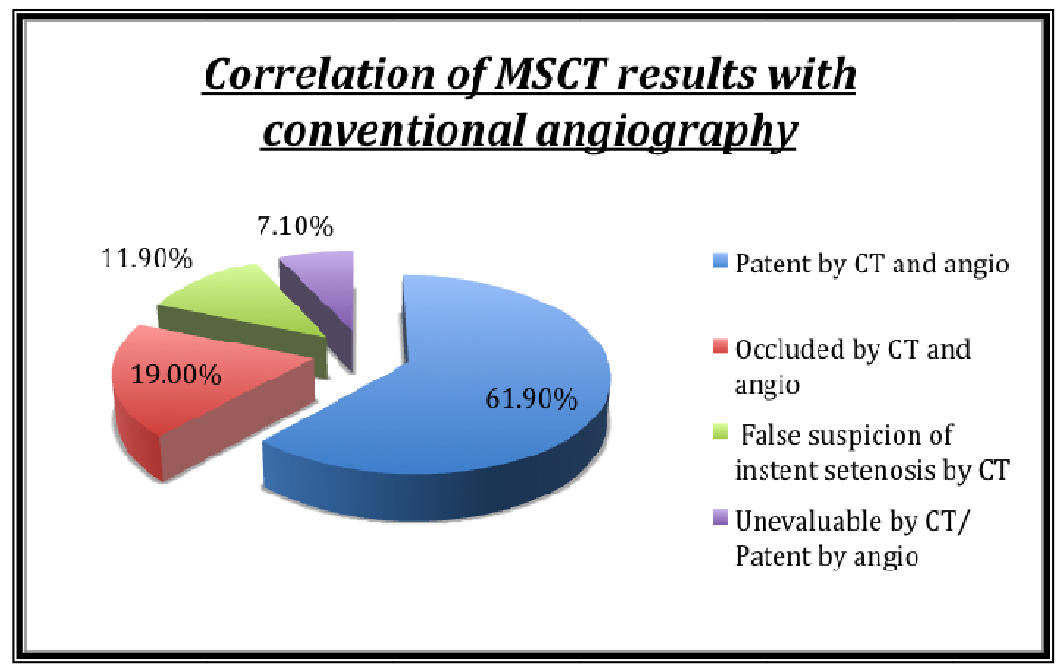

Diagram (1): Showing the relation between the results of MSCT and invasive coronary angiography in the evaluated 42 stents.

The diameters of the implanted coronary stents in our study ranging from 2.5 up to $3.5 \mathrm{~mm}$ and so if we classify our results of the assessed 42 stents by both MSCT and invasive coronary angiography in correlation to the diameter of the implanted stents, the results will be as follows: 8 stents of $3.5 \mathrm{~mm}$ in diameter show: 7 stents $(87.5 \%)$ are patent by both MSCT and invasive coronary angiography, 1 stent (12.5\%) is occluded by MSCT and invasive coronary angiography. 14 stents of $3 \mathrm{~mm}$ in diameter show: 10 stents $(71.4 \%)$ are patent by both MSCT and invasive coronary angiography, 2 stents (14.2\%) are occluded by MSCT and invasive coronary angiography and 2 stents
$(14.2 \%)$ are suspected to be re-stenosed by MSCT but not proved by invasive coronary angiography. 11 stents of $2.75 \mathrm{~mm}$ in diameter show: 7 stents $(63.6 \%)$ are patent by both MSCT and invasive coronary angiography, 1 stent $(9 \%)$ is occluded by MSCT and invasive coronary angiography and 3 stents $(27.2 \%)$ are suspected to be restenosed by MSCT two of them (18.1\%) proved to have actual restenosis by invasive coronary angiography while the other one (9\%) proved to be patent by invasive coronary angiography. 9 stents of $2.5 \mathrm{~mm}$ in diameter show: 2 stents $(22.2 \%)$ are patent by both MSCT and invasive coronary angiography, 3 stent $(33.3 \%)$ were non- 


\section{Hesham Mahmoud Mansour, et al.,}

assessable by MSCT due to thick stent struts and narrow caliber and proved their patency by invasive coronary angiography and 4 stents $(44.4 \%)$ are suspected to be restenosed by MSCT but two of them $(22.2 \%)$ proved to be actually patent by invasive coronary angiography and the other two stents $(22.2 \%)$ proved to have actual in-stent restenosis.

\section{$3.5 \mathrm{~mm}$ stent caliber}

a Patent by CT and angio $\quad$ Ocludded by CT and angio

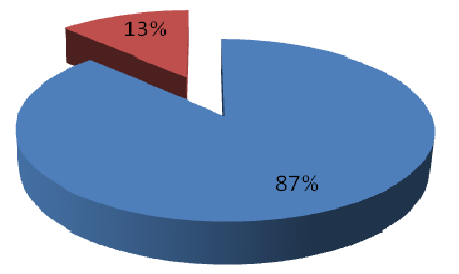

Diagram (2): Showing variable MSCT and angiographic results within $3.5 \mathrm{~mm}$ coronary stent caliber.

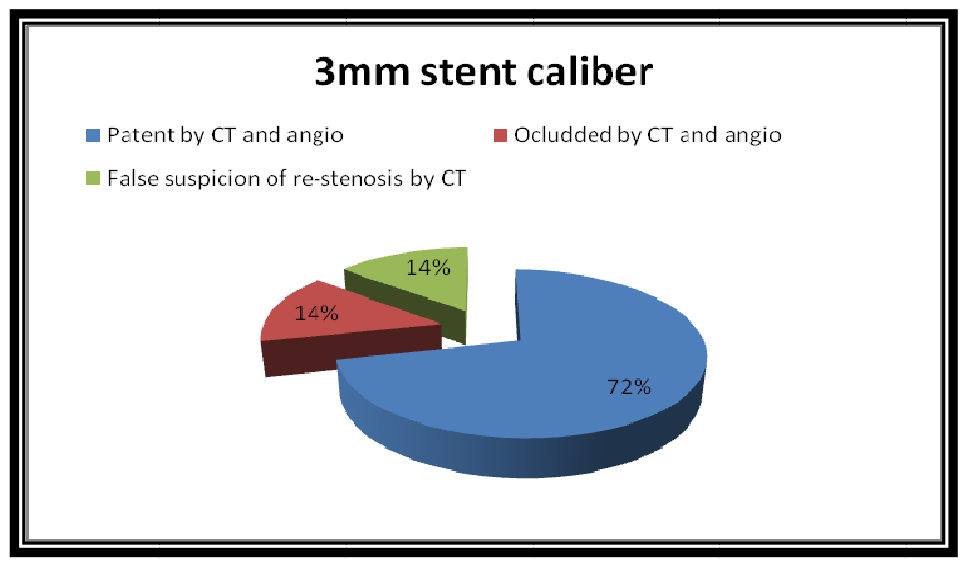

Diagram (3): Showing variable MSCT and invasive angiographic results within $3 \mathrm{~mm}$ coronary stent caliber.

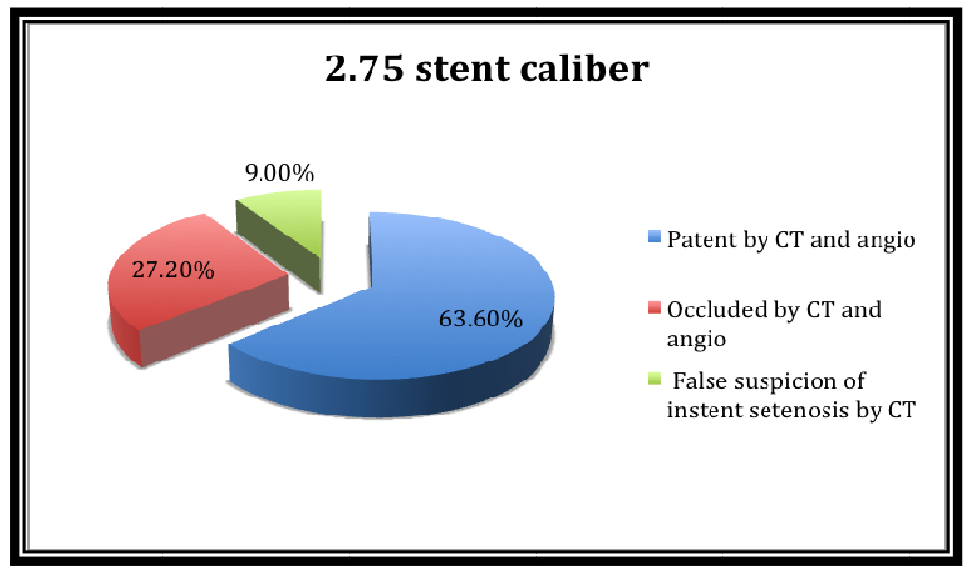

Diagram (4): Showing MSCT and invasive angiographic results within $2.75 \mathrm{~mm}$ coronary stent caliber. 


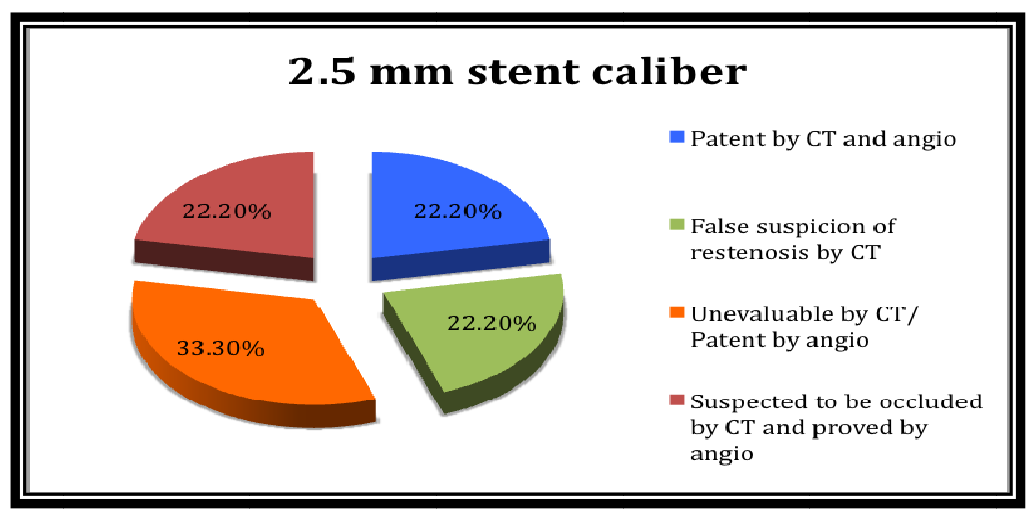

Diagram (5): Showing MSCT and invasive angiographic results within $2.5 \mathrm{~mm}$ coronary stent caliber.

In an overall view, MSCT angiography compared to the invasive coronary angiography as a gold standard technique gave us a sensitivity of $100 \%$, a specificity of about $83.8 \%$, an accuracy of about $87.1 \%$, positive predictive value (PPV) is $61.5 \%$ and negative predictive value (NPV) is $100 \%$ in the assessment of the patency of the coronary artery stents, taking into consideration proper standard CT angiography techniques in all cases.

\section{DISCUSSION:}

Invasive coronary angiography is still the technique of choice for the diagnosis of patency and in-stent restenosis of coronary artery stents. However, the main hazards and disadvanteges of invasive coronary angiography are invasiveness, patient discomfort, risk of complications and high cost. A non invasive imaging modality is wanted to evaluate patients with suspected in-stent restenosis or occlusion.

Symptomatic patients who have implanted coronary stents often represent a challenging diagnostic problem to the angiographer. The calcified, tortuous, and diffusely diseased coronary arteries alter accurate delineation of the lesions. Highquality angiographic images and complete knowledge of the coronary anatomy are required in order to adequately determine revascularization options. Performing this angiographic assessment in a noninvasive way is even more challenging.

The earliest experiments to assess the feasibility of coronary stent imaging with multi-detector CT were performed in vitro with varying collimations, contrast material concentrations, stent calibers, and stent positions within the gantry. When imaging is performed in vivo, stent-related beam hardening artifacts are a constant phenomenon, and assessment is further complicated by vessel wall calcifications, poor contrast-tonoise ratios in obese patients, and motion.

The major improvements of the recently developed multislice CT machines compared with the old scanners, include improved temporal resolution due to shorter gantry rotation time, better spatial resolution owing to sub-millimeter collimation, considerably reduced scan acquisition times and decrease radiation dose, so assessment of in-stent restenosis by MSCT is performed but still challenging. Despite the recent technical advances, the 128 slice dual source CT coronary angiography is still sensitive to arrhythmia. Persistent irregular cardiac rhythm such as a trial fibrillation and frequent extra-systoles rule out MSCT coronary angiography.

The use of multi-slice CT angiography is obtaining accelerative acceptance for noninvasive cardiac imaging. Several studies have demonstrated successful application of multi-slice CT angiography for assessment 
of coronary artery diseases and evaluation of other cardiac diseases.

Carbone et al. appraised the ability of 64- detector row CT angiography in the assessment of coronary artery stent patency on fifty-five patients (age range 4580 years) with 97 previously implanted coronary artery stents the sensitivity, specificity, positive predictive value and negative predictive value were $75,86,71$ and $89 \%$, respectively. However, nine of the 12 stented segments of $2.5-\mathrm{mm}$ diameter and 10 of the 23 stented segments of $2.75-\mathrm{mm}$ diameter were excluded from the analysis since these segments were considered as non evaluable due to blooming artifact ${ }^{(6)}$.

Wykrzykowska et al, found that 64MDCT evaluation of the stents was limited because of beam-hardening and stent-strut artifacts - that is, the blooming effect. It is particularly problematic with early stent designs where the strut thickness is greater and metals such as tantalum and gold were used. Newer stents have much thinner struts and are made predominantly of stainless steel, cobalt chromium, and nitinol. In addition, recent advances in MSCT angiography technology, such as improvement in the z-resolution, faster tube rotation, and the development of special dedicated kernels for stent evaluation, have the potential to improve the ability of MSCT angiography to accurately detect in-stent restenosis ${ }^{(7)}$.

New technical developments are bringing to the market $\mathrm{CT}$ scanners with increased performance. For many years technology in this field developed following the law of "more slices = better images". Some manufacturers are developing in this direction (Siemens Medical with 128 slices, Philips Medical with 256 slices and Toshiba Medical with 320 slices). Others are developing into higher spatial resolution (i.e. new detector hardware) technology (GE medical). Others are developing into higher temporal resolution (Siemens Medical with Dual Source technology). Others are developing also into concomitant Dual Energy platforms (GE Medical and Siemens Medical) ${ }^{(8)}$.

Another study by Andreini et al. found that 64-slice multidetector computed tomography detects in-stent re-stenosis (ISRs) in assessable coronary stents with high accuracy and specificity compared with invasive coronary angiography. An incorrect diagnosis of ISR was made by multislice computed tomography angiography in 3 of 131 stents considered free of obstruction by invasive coronary angiography. Stent diameter is a fundamental parameter affecting stent lumen assessment by multislice computed tomography. Accordingly, significantly higher specificity, positive predictive value, and negative predictive value were found in stents with a diameter $\geq 3 \mathrm{~mm}$ compared with a diameter $<3 \mathrm{~mm}$. Stent strut thickness was another determin-ing factor for lumen interpretation. All accuracy parameters were higher and positive predictive value was significantly higher in stents with a thickness $<100 \mu \mathrm{m}^{(\mathbf{9})}$.

Another study by Jun-Jie et al, found that the detection of in-stent patency by FLASH-dual source CT can be performed well with Sensitivity, specificity, positive predictive value (PPV) and negative predictive value (NPV), calculated in all stents, were $95 \%, 93 \%, 76 \%$ and $98 \%$, respectively. In stents $>=3.5 \mathrm{~mm}(\mathrm{n}=42)$, sensitivity, specificity, PPV, NPV were $100 \%$; in $3 \mathrm{~mm}$ stents $(\mathrm{n}=39)$, sensitivity and NPV were $100 \%$, specificity $97 \%$, PPV $93 \%$; in stents $\leq 2.75 \mathrm{~mm}(\mathrm{n}=26)$, sensitivity was $88 \%$, specificity $66 \%$, PPV $59 \%$, NPV $90 \%$. Five stents $\leq 2.5 \mathrm{~mm}$ were undetectable ${ }^{(\mathbf{1 0})}$.

A study by Xia et al, to investigate the diagnostic accuracy of 128-slice dual-source CT using high-pitch spiral mode in assessment of coronary stent imaging comparison with invasive coronary angiography. They found that sensitivity, specificity, and positive and negative predictive value in 
assessment of stent restenosis were $100 \%$, $97.1 \%, 83.3 \%, 100 \%$, respectively in the high pitch spiral (HPS) CT angiography ${ }^{(11)}$.

Outstanding to the artifacts caused by metal, visualization of the coronary lumen within stents by MSCT angiography is more challenging than assessment of the native coronary arteries. The type of stent and especially, stent diameter $(<3 \mathrm{~mm})$ lead to limited clinical results. Our study confirms that even with improved scanner technology, assessment of implanted coronary artery stents remains challenging.

Similar to the previous studies performed by MSCT, our study also found a significant consequence of stent diameter on assessability, with $3 \mathrm{~mm}$ being a threshold below which the rate of assessable stents is very low. The question of patency can be answered with MSCT angiography, but often only indirectly by the demonstration of filling with contrast medium both proximally and distally to the stent. the observation of distal runoff cannot be considered an absolute indicator of patency, since the presence of vessel enhancement distal to a stent could also be secondary to retrograde filling. A stent lumen of diameter less than $3 \mathrm{~mm}$ may not be directly assessable by MSCT, and the technique typically underestimates the internal stent diameter. The nature of the stent also has an important consequence on the results of MSCT angiography imaging, because artifacts due to the stent material can make the stent lumen difficult to assess, and the difficulty is only increased if the stents contain additional radio-opaque markers. Solving this problem requires higher spatial resolution, which, however, cannot be obtained without excessive radiation exposure.

Our study found that the main causes of inability to assess stent lumen by 128 - slice dual source CT scanners, are the uncontrolled high heart rates, cardiac arrythmias, large body mass index, thick stent struts and small stent diameter.

By the aforementioned analysis of the diameters of the involved coronary stents within our study the results prove the direct relation between the diameter of the implanted stent and the right $\mathrm{CT}$ assessment of its patency with adequate CT visualizetion of the wide calibered stents, while increased suspicion of in-stent restenosis and failure of evaluation in small calibered stents.

After exclusion of all non assessable stents, sensitivity for the detection of in-stent restenosis in our study was $100 \%$ and this could be due to the relatively small number of cases (with a specificity of $83.8 \%$, accuracy of $87.1 \%$, positive predictive value is $61.5 \%$ and negative predictive value is $100 \%$ ), which indicates that clinical applications might be possible if the problem of stent evaluability was solved. However, the frequency of cases with un-interpretable image quality - an overall rate of $7.14 \%$ in our study (patients with stents of $2.5 \mathrm{~mm}$ diameter) rules out the application of MSCT for coronary angiography in unselected patients with implanted coronary artery stents.

Further improvements in spatial resolution using novel detector designs as well as better reconstruction algorithms increases the utility of $\mathrm{CT}$ angiography for the assessment of patients with implanted coronary stents. So patients must be carefully selected before undergoing MSCT angiography for assessment of in-stent restenosis. Patients with the ability to breathhold and achieve low heart rates as well as patients with large $(>3.0 \mathrm{~mm})$ diameter and thin-strut, implanted stents should be considered for noninvasive assessment of instent restenosis rather than being sent directly to invasive cardiac catheterization. 


\section{Hesham Mahmoud Mansour, et al.,}
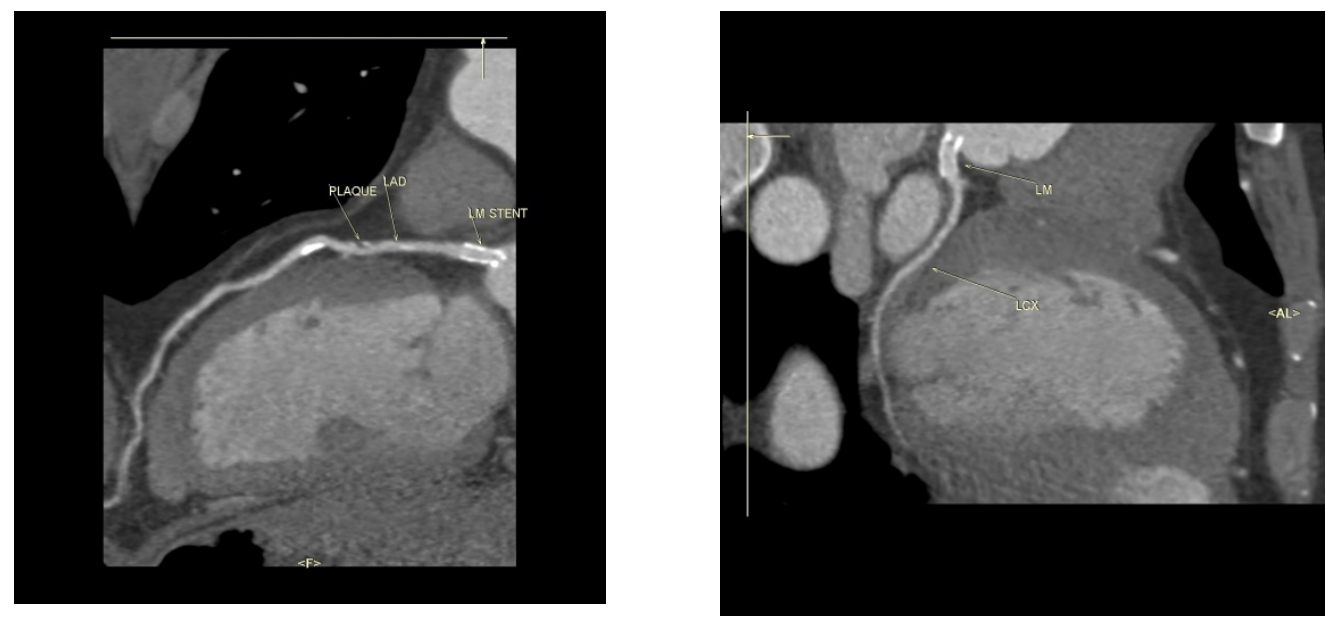

Figure (1): A 50 years old male patient with acute chest pain and history of applied coronary stent. Curved MPR images of the LM, LAD and LCX showing patent LM stent with evidence of soft plaque in mid LAD causing non-significant stenosis. Patent LCX is also noted.
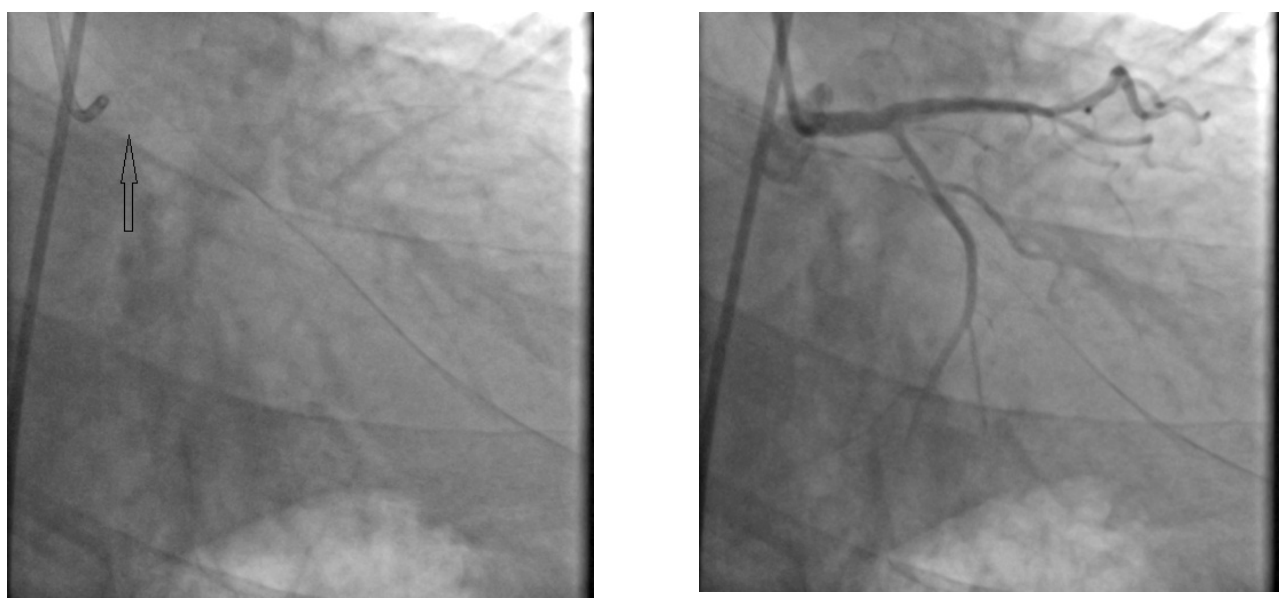

Figure (2): Invasive coronary angiography of the same patient in fig. 1 showing faint stent struts before injection of contrast (arrow) with patent stent lumen at LM. LAD and LCX arteries down to their distal segments are seen patent.



Figure (3): A 65 years old male patient with acute chest pain and history of applied coronary stent. Curved MPR image of the LAD showing non-assessable long proximal stent (due to thick stent struts). LAD afterward shows normal patency. 

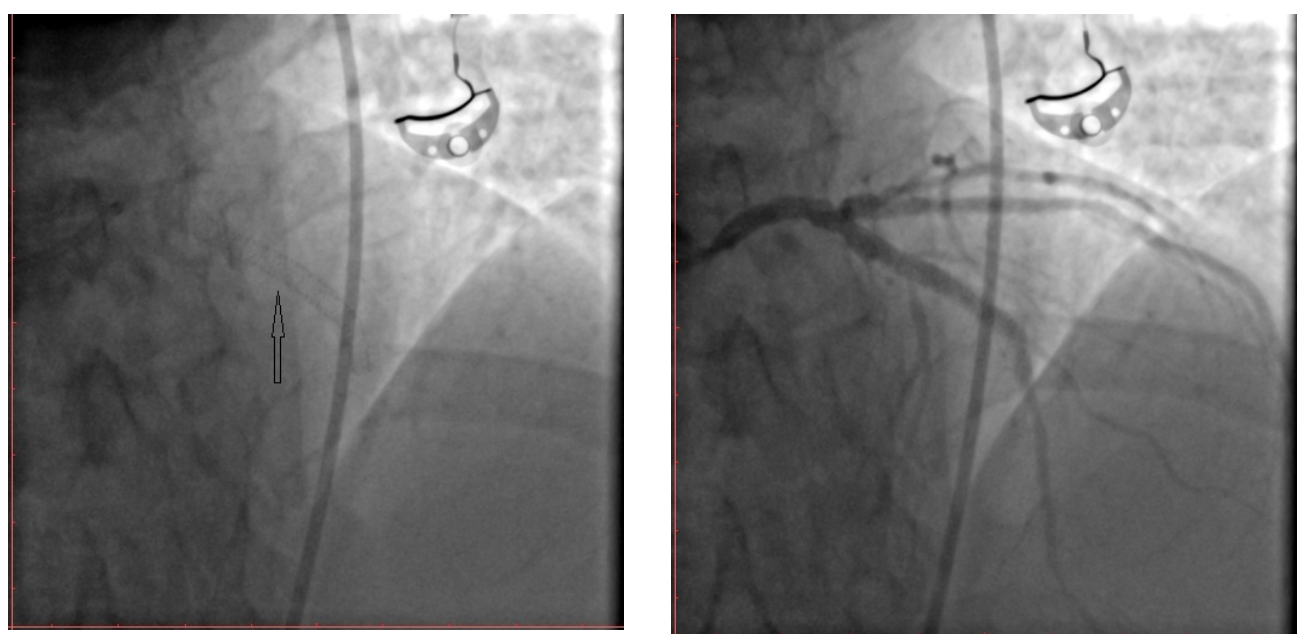

Figure (4): Invasive coronary angiography of the same patient in fig.3 showing stent struts of the LAD before injection of contrast (arrow), patency of LAD stent after contrast injection.

\section{Conclusion:}

Our study helps to identify factors that influence the assess ability of coronary artery stents by 128 -slice dual source CT scanner, namely, stent type and diameter. It shows that under certain conditions, the detection of in-stent restenosis might be possible with an accuracy that could permit clinical applications, but the non assess able stents do not allow the use of MSCT coronary angiography in unselected patients with implanted stents in coronary arteries.

So MSCT angiography as a noninvasive technique can be used for assessment of instent rest-enosis but patients must be carefully selected. Patients with the ability to breath-hold and achieve low heart rates as well as patients with large $(>3.0 \mathrm{~mm})$ diameter and thin-strut, implanted stents should be considered for noninvasive assessment of in-stent res-tenosis rather than being sent directly to invasive cardiac catheterization.

\section{REFERENCES:}

1. Park SH, Hong GR, Seo HS, Tahk SJ (2012): Stent thrombosis after successful drug-eluting stent implantation. Korean Circ J. 35: 163-71.

2. Oncel D, Oncel G, Karaca M (2013): Coronary stent patency and instent rest- enosis: determination with 64-section multidetector CT coronary angiography-initial experience. Radiology. 242: 403-9.

3. Sun Z, Ng KH (2012): Prospective versus retrospective ECG-gated multislice CT coronary angiography: a systematic review of radiation dose and diagnostic accuracy. Eur J Radiol. 81(2):e94-e100.

4. Haruhiko M, Isao T, Rika F, Yun S, Takuya I, Etsuko T, et al. (2015): Current and Novel Imaging Techniques in Coronary CT Radio Graphics. 24:991-1010.

5. Nazir SA, Alkadhi H (2014): Technical challenges of coronary CT angiography: today and tomorrow. Eur J Radiol. 79 (2):161-171.

6. Carbone I, Francone M, Algeri E, Granatelli A, Napoli A, Kirchin MA, et al. (2008): Non-invasive evaluation of coronary artery stent patency with retrospectively ECGgated 64-slice CT angiography. Eur Radiol. 18:234-243

7. Wykrzykowska JJ, Arbab-Zadeh A, Gustavo G, Julie MM, Shezhang L, Andrea V, Narinder P, Hiroyuki N, John H, Jeffrey B, Faisal K, Sheryar S, Joao L, Melvin EC (2010): Assessment of In-Stent Restenosis Using 64-MDCT:Analysis of the CORE-64 Multicenter International Trial. AJR. 194:85-92.

8. Cademartiri F, Erica M, Alessandro P, Chiara M, Annachiara A, Diego A, Valerio B, Paolo C, Nico RM, Gabriel PK, Pim JF 


\section{Hesham Mahmoud Mansour, et al.,}

(2010): CT Coronary Angiography for the follow-up of coronary stent. ACTA BIOMED. 81: 87-93.

9. Andreini D, Gianluca P, Antonio LB, Daniela T, Saima M, Erika B, Andrea A, Alberto F, Sarah C, Piero M, Fabrizio V, Giovanni B, Mauro P (2009): Comparison of Feasibility and Diagnostic Accuracy of 64-Slice Multidetector Computed Tomographic Coronary Angiography Versus Invasive Coronary Angiography Versus Intravascular Ultrasound for
Evaluation of In-Stent Restenosis. Am J Cardiol. 103:1349-1358.

10. Jun-jie Y, Xia Y, Luo-shan D, et al. (2012): Assessment of coronary artery in-stent patency by FLASH-DSCT versous coronary angiography. Heart. 98:296.

11. Xia Y, Yundai C (2012): Diagnostic accuracy of 128-slice dual-source CT using high pitch spiral mode in assessment of coronary artery stent imaging comparison with invasive coronary angiography. Heart. 98:290.

\section{دورالتقتيات الحديثة للاشعه المقطعيه متعددة المقاطع ^ ب ا مقطع مزدوج المصدر في تقييم ضيق

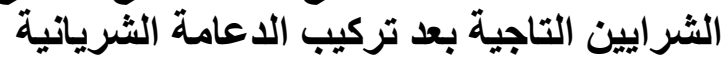

هشام محمود منصور، ايمان احمد شوقي جنيدي، امل ابراهيم احمد، وسيلة مصطفي محمد الضليفي*

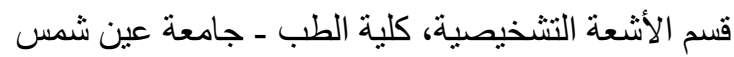

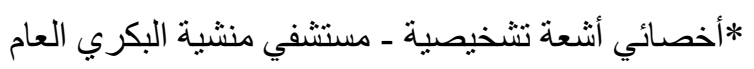

يعتبر تركيب الدعامات للشر ايين التاجية وسيلة غير جراحية فعالة وناجحة لعلاج أمر اض الثرايين التابين التاجية المتقدمة ويحدث انسداد بالدعامات للثر ايين التاجية كثير اوتزيد نسبة الانسداد بمرور السنوات.

لزمن طويل كانت القسطرة التشخيصية هي الطريقة الوحيدة لتشخيص أمر اض شر ايين القلب و الدعامات الثريانية و هي طريقة لا تخلو من بعض المضاعفات و تسبب عدم راحة للمريض با لاضافة الي ارتفاع تكلفتها ولذللك فقد كان هناك الك الت الته بحث دائم عن طرق أفضل.

ولم يكن للأشعة المقطعية أي دور في تشخيص ضيق شر ايين القلب نظر اللحركة السريعة للقلب و عدم قدرة الأجهزة

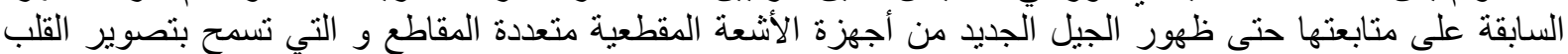

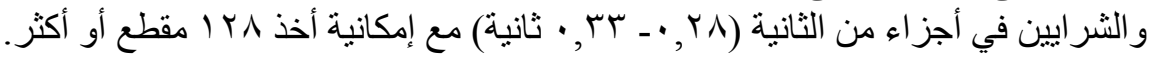

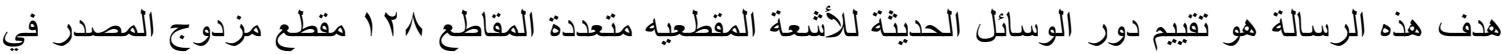

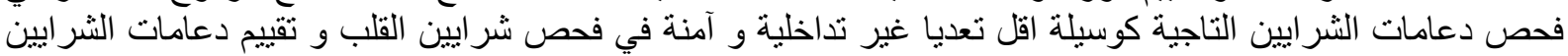

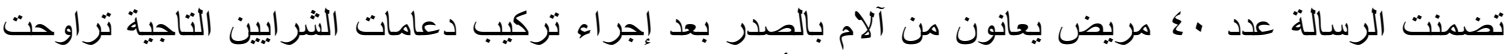

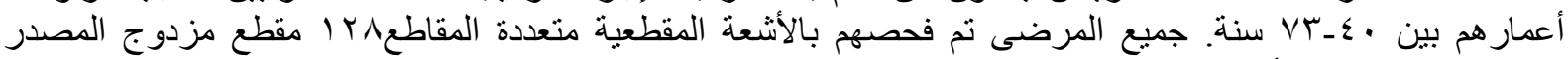
وبالقسطرة الثريانية لأجر اء المقارنات المطلوبة.

تضمنت الدراسة فحص و تقييم عدد بـ دعامة للشر ايين التاجية بالأشعة المقطعية متعددة المقاطع تمت مقارنة

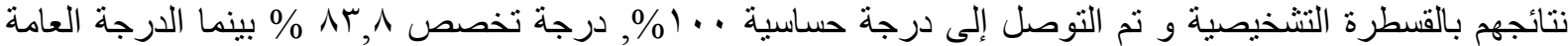

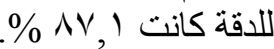

إن الأشعة المقطعية متعددة المقاطع طريقة آمنة و مضمونة لفحص دعامات الثرايين التاجية بنتائج جيدة مقارنة

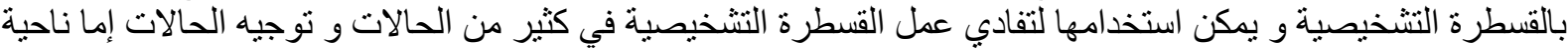
الاكتفاء بالعلاج الدو ائي أو عمل القسطرة كقطرة علاجية و ليس تشخيصية لإجر اء التوسيع و تركيب الدعامات الئل المطلوبة. و مع التطور السريع في الأجهزة و نوعية الدعامات امكن التغلب على صعوبة تقييم الدعامات ذات الحجم الصغير. 